\title{
TRITIATED THYMIDINE AUTORADIOGRAPHIC STUDY OF THE EFFECTS OF INFERIOR ALVEOLAR NERVE RESECTION ON THE PROLIFERATIVE COMPARTMENTS OF THE MOUSE INCISOR FORMATIVE TISSUES
}

\author{
D. J. ChIEGO JR ${ }^{1}$, R. M. KLeiN ${ }^{2}$ and J. K. AVerY ${ }^{1}$ \\ ${ }^{1}$ Oral Histology Laboratory, Department of Oral Biology, The University of Michigan, \\ School of Dentistry, Ann Arbor, MI 48104, U.S.A. \\ ${ }^{2}$ Department of Anatomy, University of Kansas College of Health Sciences and Hospital, \\ Kansas City, Kansas, U.S.A.
}

\begin{abstract}
Summary-At 15, 30 and 60 days after denervation, 10 mice were injected (5 controls, 5 denervated) at each time period with $0.5 \mu \mathrm{Ci} / \mathrm{gm}$ of $\left[{ }^{3} \mathrm{H}\right]$-thymidine. Denervated teeth, after 15 and 30 days, were thinner, shorter and narrower with a chalky-white appearance; by 60 days, the teeth returned to their normal predenervated appearance. The responses of the proliferative compartments of the mouse incisor varied with time after denervation, and depended on whether comparison was made to sham controls or the control side of a denervated mouse. The pre-odontoblasts were most stable in terms of $\left[{ }^{3} \mathrm{H}\right]$-thymidine labelling index with a significant decrease only at 60 days after surgery. This decrease may be due to an alteration of the inductive influence of the inner enamel epithelium and the nerve resection. The effects of nerve. resection on the inner enamel epithelium were a reduction in the labelling index on both control and clenervated sides in comparisons to sham controls and a decrease in labelling index of the denervated side when compared to contralateral control. Significant differences between the control and denervated sides of experimental mice were evident 15 days after denervation in the outer enamel epithelium, inner enamel epithelium, and pulp fibroblasts. Indirect effects (i.e. chipping of the teeth) may mask neurotrophic influences. There also appears to be a homeostatic or compensatory mechanism for attenuation of the effects of denervation in continuously erupting teeth. The effects at the early time periods emphasize the need for a study of neurotrophic effects on the cellular compartments of the tooth in the period immediately following denervation
\end{abstract}

\section{INTRODUCTION}

The inferior alveolar nerve (IAN) has been resected in several animal species in order to elucidate the role of neural influences on the growth and maintenance of the teeth. Most of these studies, from a variety of experimental animals, suggest that denervation results in an increase in the eruption rate of the ipsilateral incisor (Butcher and Taylor, 1951; Taylor and Butcher, 1951; Brown et al., 1961) although Moral and Hoseman (1919), Edwards and Kitchin (1938) and Devoto et al. (1966) found that unilateral resection of the IAN of the rat resulted in a decrease in the eruption rate of the contralateral incisor although no significant alteration in the eruption rate of the ipsilateral incisor when compared to the sham operated controls. Devoto et al. (1966) reported morphological changes, including narrowing of the tooth, discolouration and lack of pigmentation of the enamel in denervated incisors, or in some cases loss of the tooth.

Studies of the effects of denervation on the cellular products of the incisor have mainly concerned dentine formation. IAN resection causes an alteration of the normal pattern and quality of dentine formed in both the rat and rabbit incisor (Rehak, 1963; Weatherred et al., 1965; Avery et al., 1974). Avery et al. (1974) have shown a dramatic increase in reactionary dentine formation after IAN denervation associated with changes in the ameloblast layer and distortion of the inner enamel epithelium and stellate reticulum. They also noted that ameloblasts in the cervical loop area (pre-secretory ameloblasts) were affected. Denervation has also caused loss of pigmentation (Weatherred, 1965 ) and hypomineralization of enamel and replacement of enamel by cellular cementum (Avery et al., 1974).

There have been no attempts to relate these changes to alteration of proliferation within the cellular components of the incisor. Our study was designed to fill this gap in knowledge.

\section{MATERIALS AND METHODS}

We used 75 male CF-1 mice aged 30 days (Carworth Division of Charles River Breeding Labs, Wilmington, Mass.) anaesthetized with sodium pentobarbital. After retraction of the masseter muscle, the proximal end of the right mandibular incisor was exposed. The inferior alveolar nerve was exposed immediately above the end of the root of the incisor by removing the thin plate of cortical bone. At 30 days of age, the cortical bone covering the inferior alveolar nerve was still thin and easily broken and removed with sharp forceps. The nerve was dissected free from the inferior alveolar artery and vein, elevated and 
Table 1. Mean \pm standard error of the percentage of labelled cells $1 \mathrm{~h}$ after ${ }^{3} \mathrm{H}$-thymidine administration

\begin{tabular}{|c|c|c|c|c|c|c|}
\hline $\begin{array}{l}\text { Time after } \\
\text { denervation }\end{array}$ & Group & $\begin{array}{c}\text { Pre- } \\
\text { odontoblasts }\end{array}$ & $\begin{array}{c}\text { Outer } \\
\text { enamel } \\
\text { epithelium }\end{array}$ & $\begin{array}{c}\text { Inner } \\
\text { enamel } \\
\text { epithelium }\end{array}$ & $\begin{array}{l}\text { Fibr } \\
\text { Pulp }\end{array}$ & $\begin{array}{l}\text { blasts } \\
\text { Periodontal } \\
\text { ligament }\end{array}$ \\
\hline 15 days & $\begin{array}{l}\text { Control } \\
\text { Denervated }\end{array}$ & $\begin{array}{l}14.7 \pm 1.3 \\
12.2 \pm 1.4\end{array}$ & $\begin{array}{r}16.2 \pm 2.9^{*} \\
6.3 \pm 0.7^{*}\end{array}$ & $\begin{array}{r}15.3 \pm 0.6+ \\
8.4 \pm 1.4 \dagger\end{array}$ & $\begin{array}{l}12.9 \pm 0.6 \dagger \\
10.2 \pm 0.7 \dagger\end{array}$ & $\begin{array}{l}11.0 \pm 0.9_{+}^{+} \\
12.0 \pm 1.4_{+}^{+}\end{array}$ \\
\hline 30 days & $\begin{array}{l}\text { Control } \\
\text { Denervated }\end{array}$ & $\begin{array}{r}9.9 \pm 1.4 \\
11.2 \pm 1.5\end{array}$ & $\begin{array}{l}4.3 \pm 0.3 \\
3.2 \pm 0.2\end{array}$ & $\begin{array}{l}9.8 \pm 0.7 \| \\
7.9 \pm 0.7 \|\end{array}$ & $\begin{array}{l}9.4 \pm 1.7 \ddagger \\
9.3 \pm 0.8 \ddagger\end{array}$ & $\begin{array}{l}9.8 \pm 0.3 \\
9.9 \pm 0.8\end{array}$ \\
\hline \multirow[t]{2}{*}{60 days } & $\begin{array}{l}\text { Control } \\
\text { Denervated }\end{array}$ & $\begin{array}{l}7.8 \pm 1.7 \ddagger \\
8.2 \pm 2.0 \ddagger\end{array}$ & $\begin{array}{l}6.0 \pm 0.5 \\
5.1 \pm 1.1\end{array}$ & $\begin{array}{l}11.5 \pm 2.2 \\
11.6 \pm 2.1 \|\end{array}$ & $\begin{array}{l}12.8 \pm 3.1 \pm \\
11.1 \pm 2.3 \pm\end{array}$ & $\begin{array}{c}11.1 \pm 0.15 \\
8.9 \pm 1.4\end{array}$ \\
\hline & $\begin{array}{l}\text { Sham-controls } \\
\text { (SC) }\end{array}$ & $10.6 \pm 2.3$ & $5.5 \pm 1.3$ & $16.5 \pm 1.7$ & $15.1 \pm 1.5$ & $7.9 \pm 1.0$ \\
\hline
\end{tabular}

* Control and denervated sides differ $p<0.01$.

+ Control and denervated sides differ $p<0.05$, SC differ from denervated side $p<0.05$.

$\ddagger$ Control and denervated sides differ NS, both differ from SC $p<0.05$.

$\S$ Control side differs $p<0.01$ from SC.

If All values (operated and unoperated) differ $p<0.05$ from SC at 30 and 60 days.

resected. Approximately $2 \mathrm{~mm}$ of the nerve was removed to prevent re-innervation within the time course of the experiment. The masseter muscle and the skin were re-approximated and sutured with 3-0 surgical silk. After surgery, the animals were returned to their cages, segregated according to sex, and their daily weights were determined in order to evaluate possible alterations in body growth associated with the denervation procedure.

A sham-operated control animal was one in which all the above surgical procedures were accomplished except for resection of the nerve. The contralateral unoperated jaws of both the experimental and shamoperated animals were used as controls.

At 15,30 and 60 days after denervation, 5 denervated and 5 control mice were injected with $0.5 \mu \mathrm{Ci} / \mathrm{g}$ body weight of $\left[{ }^{3} \mathrm{H}\right]$-thymidine $\left({ }^{3} \mathrm{H}-\mathrm{TdR}\right)$ with a specific activity of $6.7 \mathrm{Ci} / \mathrm{mmol}$ (New England Nuclear, Boston, Mass.) and killed 1 h later. The mandibles were split in half by cutting through the sagittal symphysis, fixed in 10 per cent neutral buffered formalin, washed, and demineralized in sodium citrateformic acid solution for 28 days. After washing for $24 \mathrm{~h}$ in running tap water, the mandibles were dehydrated in graded concentrations of ethanol, processed routinely for paraffin-wax embedding, oriented in the sagittal plane and sectioned through the cervical loop region of the incisors. Five-micrometre sections were cut and mounted on glass slides, dipped in NTB-2 (Eastman Kodak Co., Rochester, N.Y.) and stored in the dark at $4^{\circ} \mathrm{C}$ for the 21-day exposure period. Slides were subsequently developed in D-19 developer, washed briefly in distilled water, fixed in Kodak Fixer, washed in running tap water and stained lightly with Harris haematoxylin and eosin. Resulting autoradiographs had an average background of 1.0 grain/cell.

The percentage of ${ }^{3} \mathrm{H}$-TdR-labelled cells was determined at each of the 3 time intervals following denervation for incisors from control and denervated sides and for sham-operated and unoperated controls. The proliferative compartments of the incisor were defined as follows:

Pre-secretory ameloblasts were defined as the layer of ameloblasts from the extreme apical end of the incisor (the point of maximum convexity; Warshawsky and Smith, 1974) through the region of ameoloblasts facing the pulp (odontogenic organ) and the apical $1 / 3$ of the ameloblasts facing the dentine (enamel organ; Warshawsky and Smith, 1974). All other cell types were defined relative to the inner enamel epithelium as shown in Fig. 1.

One thousand cells were counted per incisor (right or left) for each cell type in the incisor. Labelling indices were compared at the three time intervals for the denervated versus the contralateral control using a $t$-test for paired observation, and an unpaired $t$-test for testing the denervated or contralateral control versus the sham control.

\section{RESULTS}

\section{Morphology}

Denervated teeth appeared shorter, thinner, and narrower at 15 and 30 days. The enamel had a chalky white (porcelain) appearance at 15 days after denervation. At 30 days, the denervated teeth still showed an abnormal porcelain-like appearance of the enamel and some teeth were chipped or broken. By 60 days, the teeth appeared normal with no visible alteration of length, width, or consistency of the enamel or dentine.

\section{$\left[{ }^{3} \mathrm{H}\right]$-thymidine labelled cells}

The results of ${ }^{3} \mathrm{H}-\mathrm{TdR}$ labelling studies are shown in Table 1. Labelling index data are compared for both sham controls and unoperated (contralateral) controls versus the operated (denervated) incisor. Preodontoblasts of denervated teeth did not show significant differences between contralateral control and denervated incisors but did show a difference when compared to the sham controls at 60 days after surgery. The cells of the outer enamel epithelium showed a dramatic increase in contralateral controls at 15 
days when compared to sham controls or denervated. The presecretory ameloblasts of the inner enamel epithelium had a decreased labelling index at 15 days in the denervated animals when compared to the contralateral controls and were significantly different at all time periods when tested against the sham controls. Pulpal fibroblasts showed significant differences between contralateral control and denervated incisors of IAN-resectioned mice only at 15 days after surgery and were significantly different from sham controls at all 3 time periods (15, 30 and 60 days). The denervated periodontal ligament fibroblasts (at 15 days) had an increased labelling index when compared to the sham controls.

\section{DISCUSSION}

The morphological changes in denervated mouse incisors were similar to the changes described in other species possessing continuously erupting incisors (Taylor and Butcher, 1951; Ronning and Isotupa, 1973) and which Isotupa and Ronning (1977) attributed to interference with the blood supply of the incisor. However, Taylor and Butcher (1951) found no alteration of eruption rate after cutting the internal carotid, but did find an acceleration of incisor eruption rate after IAN resection. In our study, inspection both during surgery and post mortem revealed no damage to the blood vessels and no regeneration of the resected IAN. This would implicate the IAN as a regulative factor of proliferation in those cellular compartments with alteration of labelling index after IAN denervation.

\section{Presecretory ameloblasts (inner enamel epithelium)}

Cell production rates and cell kinetics of the inner enamel epithelium have been related to attrition and occlusion in the rat incisor after impeded and unimpeded eruption (Bar-Lev et al., 1977). Under conditions of "low impediment probability" incisor eruption and cell production rates in the inner enamel epithelium increased (Bar-Lev et al., 1977). Since there may be a decrease in occlusal forces in the denervated animals (Taylor and Butcher, 1951) one might expect an increase in cell division and labelling index within the inner enamel epithelium. If eruption rate decreases in contralateral control (Devoto et al., 1966) then one would expect a lower labelling index in the contralateral control as compared to sham control. The decrease in labelling index which occurs in denervation as compared to contralateral control or sham control at 15 days, and in both contralateral control and denervation as compared to sham control at 30 and 60 days after denervation, would seem to indicate a different effect on the inner enamel epithelium. However, labelling index is a reflection of several factors - cell migration, growth fraction, the duration of DNA synthetic or $S$ phase $\left(T_{S}\right)$ and generation cycle time $\left(T_{C}\right)$ of the presecretory ameloblast cell cycle $\left[\mathrm{LI}_{\mathrm{obs}}=\right.$ growth fraction $\times \mathrm{LI}_{\text {exp }}$, where $\mathrm{LI}_{\text {exp }}=$ $\left.\left(T_{S} / T_{C}\right)\right]$. It is therefore possible that accelerated eruption in denervation is associated with cells migrating prematurely in the incisor with a lower growth fraction in the proliferative compartment and a faster rate of migration to the functional compartment. Therefore, a shorter $S$ and $T_{C}$ period and a decrease in growth fraction could result in a lower labelling index within the presecretory ameloblast compartment. Measurement of these parameters during the temporal sequence of events after denervation may help elucidate some of the complex changes occurring between contralateral and ipsilateral incisors after unilateral IAN resection.

\section{Outer enamel epithelium}

Warshawsky and Smith (1974) found only infrequent mitoses in this layer of the rat incisor. Hwang and Tonna (1965) found only slight $\left[{ }^{3} \mathrm{H}\right]$-thymidine labelling in the outer enamel epithelium, stellate reticulum, and stratum intermedium (5.2 per cent). The function of these layers is unknown although the outer enamel epithelium is hypothesized to regulate the flow of tissue fluid to and from the stellate reticulum (Kallenbach, 1978). Only one study has analyzed cell division in the outer enamel epithelium. Grewe and Felts (1963) showed that the lack of occlusion found in neonatal mice incisors could be correlated with higher rates of DNA labelling in the outer enamel epithelium, stellate reticulum, and stratum intermedium. The differences in outer enamel epithelium labelling indices may be associated with changes in occlusion or eruption rate which occur immediately after IAN resection; the effects are not present at 30 or 60 days after surgical denervation. The changes which occur in the outer enamel epithelium appear to be unrelated to events in the inner enamel epithelium, which corroborates the work of Osman and Ruch (1976) who have shown a dissociation between the values of mitotic index in the outer and inner enamel epithelium of developing molars and incisors of mice. However, the mitotic potential of the outer enamel epithelium has been noted previously in the rhesus monkey during amelogenesis (Engler et al., 1965) and may aid in the adaptation of the incisor to denervation in the present study.

\section{Pulp and periodontal ligament fibroblasts}

Pulp and periodontal ligament fibroblasts differ in their response to IAN denervation. Although at most time intervals there are no differences in either group between contralateral control and the denervated incisor (except in the pulp at 15 days), pulp fibroblasts have a lower labelling index and periodontal ligament fibroblasts have a higher labelling index than sham control at all time intervals. The possible relationships of pulp and periodontal ligament fibroblast proliferation have not been investigated.

Increases in cell proliferative activity within the periodontal ligament have been correlated with the functional demands on the periodontium. Weiss et al. (1968) found the highest $\left[{ }^{3} \mathrm{H}\right]$-thymidine-labelling indices in the regions of the rat periodontium under the greatest masticatory, movement and attached forces (crestal surface of the interradicular septum and interdental periodontal ligament mesial surface, mesial root) while the lowest labelling indices values were obtained along the alveolar ridge, a region subject to far less functional demand (Weiss et al., 1968). Attempts to relate cell proliferation in the periodontal ligament to eruption have used demecolcine administration to block dividing cells in metaphase (Chiba et al., 1968; Berkovitz, 1972a; Main and Adams, 1966). 
Chiba et al. (1968) and Ber..ovitz (1972a) found a decrease in eruption rate after administration of that stathmokinetic drug. However, the general effects of demecolcine on all mitotically active cells and on all microtubular-related functions (including secretion) prevents any definitive statements on the role of either periodontal ligament or pulp fibroblasts proliferation in alteration of eruption rate. In addition, Berkovitz (1972b) and Pitaru et al. (1976) have shown that removal of the basal (progenitive) area of the periodontal ligament of the rat incisor eliminates a large proportion of the proliferating periodontal ligament fibroblasts, but does not influence the rate of eruption.

The pulp fibroblasts had consistently lower values for both the denervated incisors and contralateral controls when compared to the sham control. At 15 days there was a significant decrease in denervated control as compared to the contralateral control. Decreases in pulp fibroblast proliferation are associated with trauma. Cyclophosphamide in doses of $120 \mathrm{mg} / \mathrm{kg}$ produces an acellularity among the relatively undifferentiated mesenchymal cells of the basal part of the pulp (Adatia, 1975). A similar acellularity has been found after triethylamine melamine administration, which almost completely inhibits mitosis in the dental pulp (Main and Adams, 1966) although DNA synthesis appears to continue among the remaining viable cells (Hendry et al., 1951; Main and Adams, 1966). Pulp fibroblast labelling indices also decreases (62.5 per cent) during increased occlusion associated with the development of the mouse mandibular incisors, although no standard errors or statistical analysis were provided in that study (Grewe and Felts, 1968).

\section{Pre-odontoblasts}

The pre-odontoblasts surprisingly showed no significant differences in labelling indices at the 15 and 30 day periods in any of the statistical comparisons. However, there was significant decrease in the labelling index at 60 days after denervation when the denervated and control were compared to the sham control. The relationship of the odontoblasts to the ameloblasts is an extremely complex system where the differentiation of odontoblasts depends upon the presence of the inner enamel epithelium, while the maturation of ameloblasts from presecretory ameloblasts within the inner enamel epithelium depends upon the inductive influence of the odontoblasts (Marsland, 1951). It is possible that the decrease in pre-odontoblast-labelling indices during the duration of the present investigation is due to an alteration of the inductive influence of the inner enamel epithelium by IAN resection.

Neurotrophism and the proliferative compartments of the mouse incisor

Although there has been much controversy over the role of the IAN in altering the eruption rate of the continuously erupting incisors of several species, most investigators have viewed the innervation totally from the viewpoint of loss of sympathetic vasoconstrictor fibers or loss of sensation within the tooth. In the present study it appears that there is no clearly defined role of the IAN in regulation of the prolifera- tive compartments of the continuously erupting incisors of the mouse. It is probable that mice, through loss of propricception and sensation in the incisors, treat their teeth "more carelessly" (Taylor and Butcher, 1951) producing a rapid attrition and occlusal effect on the incisors. These effects cannot be easily controlled during a long-term experiment, but may indirectly produce differences in the adaptation of the rat incisor to loss of innervation. Neurotrophic effects in the limited definition of chemical control of growth by axonal transport of materials from the IAN have not been analyzed to a great extent in the continuously erupting incisor, except for the affect of innervation on dentine formation. Kroeger (1968) found a bradykinin-like material in the pulp which he believes affects the odontoblasts in a trophic manner. Byers and Kish (1976) measured axonal transport from the trigeminal ganglion into the dentine; however, this transport into the odontoblasts does not necessarily reflect movement of a neurotrophic factor. There has been other evidence from retrograde horseradish peroxidase transport studies of a feedback influence from the pulp on the innervating neurons (Arvidsson, 1975; Chiego et al., 1980). The possible role of neurotrophic influence on the continuously erupting incisor of the mouse needs to be analyzed further in an attempt to elucidate a pattern of change in DNA, RNA, and protein synthesis in different compartments of the mouse incisor as has been done for the regenerating amphibian limb (Singer, 1974).

Acknowledgements-This research was supported by U.S.P.H.S. Research Grant DE-01604 from the National Institute of Dental Research and N.I.H. Grant 5-S01-RR5373 to the University of Kansas Medical Center.

\section{REFERENCES}

Adatia A. K. 1975. The effects of cyclophosphamide on odontogenesis in the rat. Archs oral Biol. 20, 141-144.

Arvidsson J. 1975. Location of cat trigeminal ganglion cells innervating dental pulp of upper and lower canines studied by retrograde transport of horseradish peroxidase Brain Res. 99, 135-139.

Avery J. K., Cox C. F. and Corpron R. E. 1974. The effects of combined nerve resection and cavity preparation and restoration on response dentine formation in rabbit incisors. Archs oral Biol. 19, 539-548.

Avery J. K., Strachan D. S., Corpron R. E. and Cox C. F. 1971. Morphological studies of the altered pulps of the New Zealand white rabbit after resection of the inferior alveolar nerve and/or the superior cervical ganglion. Anat. Rec. 171, 495-508.

Bar-Lev M., Zajicek G. Michaeli Y. and Weinreb M. M. 1976. Inner enamel epithelium cell production rates. Cell Tissue Kinet. 9, 413-418.

Berkovitz B. K. B. 1972a. The effect of preventing eruption on the proliferative basal tissues of the rat lower incisor. Archs oral Biol. 17, 1279-1288.

Berkovitz B. K. B. 1972b. The effect of demecolcine and of thanomelamine on the unimpeded eruption rate of normal and root resected incisor teeth in rats. Archs oral Biol. 17, 937-947.

Brown G. N., Kupfer S. R. and Darlington C. G. 1961. Effects of inferior alveolar nerve severance on the eruption rate of the mandibular incisor in the 10-day old Wistar albino rat, Oral Surg. 14, 1227-1255.

Butcher E. O. and Taylor A. C. 1951. The effects of denervation and ischemia upon the teeth of the monkey. $J$. dent. Res. 30, 265-275. 
Byers M. R. and Kish S. J. 1976. Delineation of somatic nerve endings in rat teeth by radioautography of axontransported protein. J. dent. Res. 55, 419-425.

Chiba M., Narraway J. M. and Ness A. R. 1968. Impeded and unimpeded eruption of the mandibular incisor of the adult male rat and its stoppage by demecolcine. J. dent. Res. 47, 986. Abstract.

Chiego D. J. Jr, Cox C. F. and Avery J. K. 1980. H ${ }^{3}$-HRP analysis of the nerve supply to primate teeth. $J$. dent. Res. 59, 736-744.

Devoto F. C. H., Arias N. H. and Perrotto B. M. 1966. Growth of rats' lower incisor teeth after unilateral section of alveolar nerve. J. dent. Res. 45, 1078-1082.

Edwards L. F. and Kitchen P. C. 1938. Does resection of nerves supplying the mandible affect development of the teeth? J. dent. Res. 49, 1537-1540.

Engler W. O., Ramfjord S. P. and Hiniker J. J. 1965. Mitotic potential of the enamel organ of the rhesus monkey. $J$. dent. Res. 44, 1285-1290.

Grewe J. M. and Felts W. J. L. 1968. Influence of occlusion on the cellular activity of mouse mandible incisors. $J$. dent. Res. 47, 65-69.

Hendry J. A., Homer R. F., Rose F. L. and Walpole A. L. 1951. Cytotoxic agents: III Derivatives of (-)ethyleneimene. Br. J. Pharmac. 6, 375-410.

Hwang W. S. S. and Tonna E. A. 1965. Autoradiographic analysis of labeling indices and migration rates of cellular component of mouse incisors using tritiated thymidine ( $\left.\mathrm{H}^{3} \mathrm{TDR}\right)$. J. dent. Res. 44, 42-53.

Isotupa K. and Ronning, O. 1977. Changes in the dentition of the guinea pig following total section of the inferior alveolar nerve and vessels. Acta anat. 98, 71-76.

Kallenbach E. 1978. Fine structure of the stratum intermedium, stellate reticulum, and outer enamel epithelium in the enamel organ of the kitten. J. Anat. 126, 247-260.

Kroeger D. C. 1968. Possible role of neurohumoral substances in the pulp. In: Biology of the Dental Pulp Organ: A Symposium (Edited by Finn S. B.) pp. 333-352. Univ. Alabama Press, Birmingham, U.S.A.

Main J. H. P. and Adams D. 1966. Experiments on the rat incisor into the cellular proliferation and blood pressure theories of tooth eruption. Archs oral Biol. 11, 163-178.

Marsland E. A. 1951. A histological investigation of amelogenesis in rats-I: Matrix formation. Br. dent. J. 91, 251-261.
Moral H. and Hosemann G. 1919. Ueber den Einflusse der Nerven auf das Wachstum der Zahne. Anat. Hefte 57, 203-209.

Osman A. and Ruch J. V. 1976. Répartition topographique des mitoses dans l'incisive et la (lère) molaire inférieures de l'embryon des souris. $J$. Biol. buccale 4, 331-348.

Pitaru S., Michaeli Y., Zajicek G. and Weinreb M. M. 1976. Role of attrition and occlusal contact in the physiology of the rat incisor. X. The part played by the periodontal ligament in the eruptive process. J. dent. Res. 55, 819-824.

Rehak J. R. 1963. Course and resection of the inferior alveolar nerve in the albino rat. $J$, dent. Res. 42 , 1159-1168.

Roberts W. E., Chase D. C. and Jee W. S. S. 1974. Counts of labeled mitoses in the orthodontically stimulated periodontal ligament in the rat. Archs oral Biol. 19, 665-670.

Robins M. W. 1967. The proliferation of pulp cells in rat incisors. Archs oral Biol. 12, 487-501.

Ronning O. and Isotupa K. 1973. Changes in the dentition of the guinea pig following partial section of the inferior alveolar nerve. Archs oral Biol. 18, 1050-1062.

Singer M. 1974. Neurotrophic control of limb regeneration in the newt. In: Trophic Functions of the Neuron (Edited by Drachman D. B.) pp. 228, 304-322. N.Y. Academy of Science, New York.

Taylor A. C. and Butcher E. O. 1951. The regulation of eruption rate in the incisor teeth of the white rat. J. exp. Zool. 117, 165-188.

Warshawsky H. and Smith C. E. 1974. Morphological classification of rat incisor ameloblasts. Anat. Rec. 179, 423-466.

Weatherred J. G., Kroeger D. C. and Smith E. L. 1963. Pressure responsible in the dental pulp chamber to inferior alveolar nerve stimulation. Fedn Proc. Fedn Am. Socs exp. Biol. 22, 287. Abstract 756.

Weatherred J. G. 1965. Peripheral nervous system effects in the dental pulp of the rat and dog. Ph.D. Thesis. The University of Texas, Austin, Texas.

Weiss R., Stahl S. S. and Tonna E. A. 1968. Functional demands on the cell proliferative activity of the rat periodontium studied autoradiographically. J. dent. Res. 47, 1153-1156. 
Plate 1.

Fig. 1. The proliferative compartment of the mouse incisor is shown in this photomicrograph. The compartment is divided into: (A) outer enamel epithelium, (B) stellate reticulum, (C) inner enamel epithelium, (D) pre-odontoblasts, (E) pulpal fibroblasts, (F) stratum intermedium and (G) periodontal ligament fibroblasts. The arrow in the bottom right corner indicates an unlabelled fibroblast in telophase. Haematoxylin and eosin. $\times 40$ 


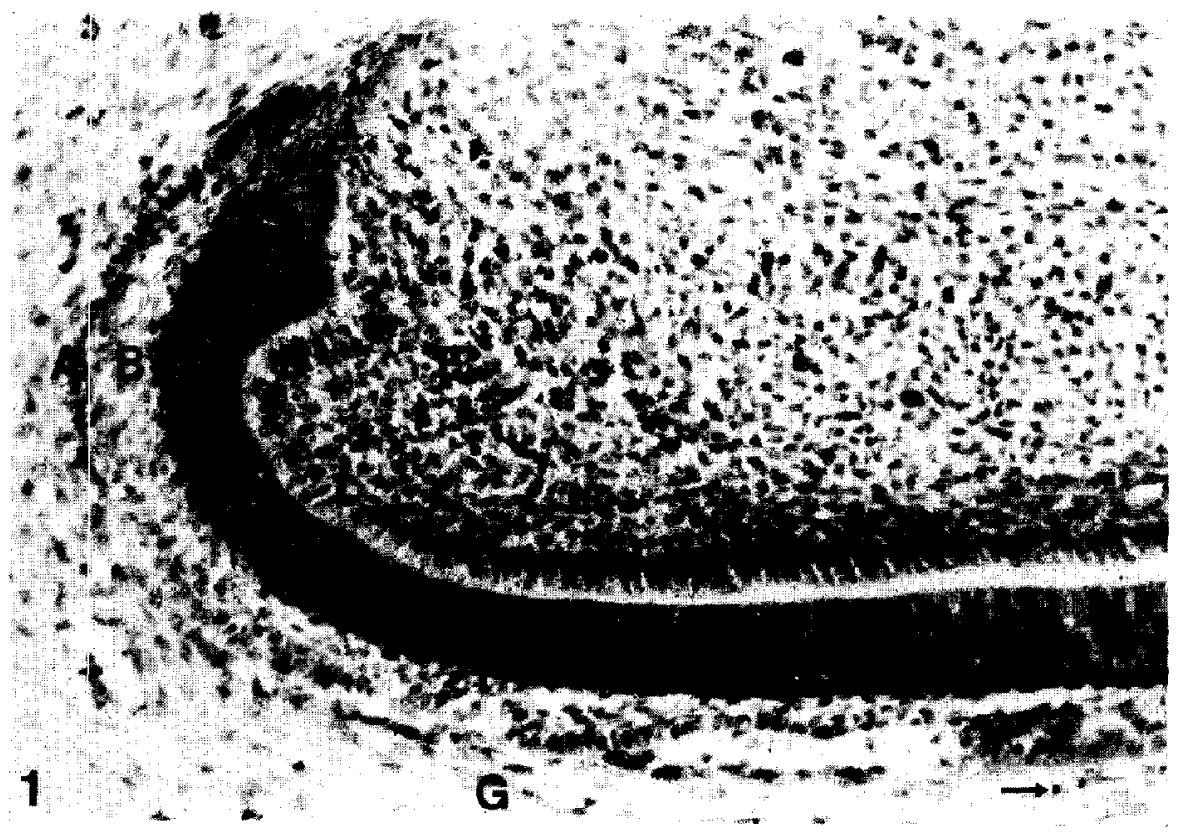

Plate 1. 